\title{
DULCINEA, NOMBRE PASTORIL
}

Dulcinea es el tercer nombre inventado por el ingenioso hidalgo en el primer capítulo del Quijote. Tras dedicar cuatro (!) días a la invención del nombre Rocinante ${ }^{1}$, y luego ocho (!) a la del suyo propio, termina fabricando el de su dama, cuando en su imaginación piensa matar a un gigante Caraculiambro y ve que necesita "tener a quien enviár[selo] presentado". El capítulo primero es, pues, en parte un capítulo "onomástico"; dedicado principalmente a retratar al héroe y a describir su pasión, también configura en términos generales ese mundo heroico que será tema del libro, representándolo desde el principio con sus respectivos nombres propios (sin olvidar entre ellos el del "jayán”, quintaesencia de lo caballeresco, con su lugar jayanesco, Malindrania; recuérdense las palabras del Cura en I, 5: "TTa, ta! . . ¿Jayanes hay en la danza?") ${ }^{2}$.

1 El dar nombre al caballo antes que al amo no es pura parodia. Sabida es la importancia del caballo en el mundo medieval y caballeresco. El mismo Ramón Llull, en su Libro de la orden de caballeria (1275), discurre largamente sobre el caballo antes de describir los deberes del caballero: "Se buscó también entre las bestias la más bella, que corre más, que puede aguantar mayor trabajo y que conviene más al servicio del hombre. $Y$ porque el caballo es el bruto más noble y más apto para servirle, por esto fue escogido y dado a aquel hombre que entre mil fue escogido, y éste es el motivo por que aquel hombre se llama caballero" (Obras literarias, ed. M. Batllori, Madrid, 1947, p. 109). También Llull quiere fijar al principio el "carácter" del caballero a base de su nombre, es decir, la "etimología” del personaje principal (véase la nota 2).

$=$ Es complicada la historia de los nombres propios en la literatura. La técnica de jugar con sus etimologías y la de crear nombres alusivos se remontan al pensamiento y a la literatura de la Antigüedad, y se relacionan con un antiguo canon de la retórica estudiado por Platón en el Crátilo. “¿Es posible đeducir del nombre de una cosa su esencia? La antigua retórica afirma que sí es posible" (E. R. Curtus, Literatura europea y Edad Media latina, trad. M. Frenk Alatorre y A. Alatorre, México, 1955, p. 692). E1 proceso puede decirse que va del "nombre a la cosa, del uerbum a la res" (ibid., p. 694); ésa es la base de las Etymologiae de San Isidoro. Véase el excursus de Curtius, "La etimología como forma de pensamiento", y mis estudios "Spanish baroque parody in mock titles and fictional names", $R P h, 15$ (1961), 29-39, y "Moralallegorical names in Gracián's Criticón”, Names, 9 (1961), 215-233. El proceso aparece en toda la literatura medieval, autorizado por los dos Testamentos. En su artículo "Perspectivismo lingüístico en el Quijote" (Lingüistica e historia literaria, Madrid, 1955, p. 173) observa LEo SPITzer que el cambio de nombre, 
Menéndez Pelayo ${ }^{3}$ sugirió por primera vez que Cervantes tomó el nombre Dulcinea del de un pastor que aparece en la obra de Antonio de Lofrasso, Los diez libros de fortuna de amor (1573). Será necesario comentar brevemente la tradición de la onomástica pastoril para llegar a la debida comprensión del nombre que escogió Cervantes. Un pastor Dulcineo ilustra con su nombre el carácter "dulce" atribuido al hombre que vive en el ambiente ideal de la Edad de Oro.

Quizá fue Virgilio quien enseñó al Renacimiento una faceta de la onomástica pastoril: su Melibeo simbolizaba también lo "dulce" del carácter humano en la Edad Dorada, al menos para los seguidores de Virgilio en la nueva época ${ }^{4}$. Probablemente es virgiliano el Meliseo de Sannazaro, que existía ya (Melisseus o Melissus) en la Antigüedad, pero que fue asimilado a lo pastoril por el autor de la Arcadia. Los nombres prototípicos en mel-se fundan, sin duda,

tan constante en los libros de caballerías y parodiado por Cervantes (Don Quijote, Caballero de la Triste Figura), procede de la costumbre de tomar un nombre nuevo después del bautismo. La corriente está todavía muy viva en el Renacimiento, y fray Luis de León dice en el prólogo de Los nombres de Cristo: "... el nombre es como imagen de la cosa de quien se dice, o la misma cosa disfrazada de otra manera" (Obras completas, ed. F. García, Madrid, 1944, p. 394). Gracián dedica un capítulo de su Agudeza y arte de ingenio $(1642,1648)$ a la "Agudeza nominal", o sea a la técnica de manejar nombres propios de modo que expresen sus más escondidos significados, y no vacilia en dar al nombre de Dios una interpretación propia: ". . dividido está di. ciendo: Di os, Di os la vida, Di os la hacienda, Di os la tierra, Di os el cielo, Di os el ser, Di os mi gracia, Di os a mí mismo, Di os lo todo, ...de modo que del dar, del hacernos todo bien, tomó el Señor su santísimo y augustísimo renombre de Dios en nuestra lengua española" (Obras completas, ed. E. Corren Calderón, Madrid, 1944, p. 189). Cervantes y Quevedo (véase mi "Onomastic invention in the Buscón", $H R, 29,1961,15-92)$ son expertos en el manejo de nombres, y un casi-contemporáneo de ellos, jugando con la creación de unos nombres absurdos, y como recordando las palabras de Platón transferidas ya a la litèratura, al mismo tiempo que fija y define la naturaleza del capítulo "primero" del Quijote, comenta: "...que para cualesquier progresos de la definición es casi preciso empezar por el nombre, que con eso se distinguen las personas" (B. Remiro DE NAvarra, Los peligros de Madrid [1646], ed. Madrid, 1956, p. 104). Cf. Quijote, ed. F. Rodriguez Marín, Madrid, 1947-49, t. 1, p. 98. (Cito siempre por esta edición).

3 Origenes de la novela, ed. Buenos Aires, 1945, t. 2, 1. go8.

* II significado del nombre virgiliano no debe de ser muy diferente del atribuido a Meliboia: que nutre con dulce alimento (die mit süsser Nahrung' Nährende': Pauly-Wissowa, Real-Enzylopädie; cf. bibliografía en el artículo respectivo). Pero en romance el nombre ya sólo alude al 'carácter dulce'. Hay, es cierto, varias Meliboea, diosas menores, ninfas, etc., en la Antigüedad, además de la ciudad del mismo nombre en Tesalia, mencionada en la Eneida, pero dudo que Rojas pensara en ellas: evidentemente partió del Melibeo de las églogas: virgilianas. Hace de la ninfa Callisto un varón, y del pastor Meliboeus una mujer; al trocar así los géneros, repite un ejercicio grato a los humanistas del Renacimiento. Remiro de Navarra (supra, nota 2) hasta crea - con evidente 
en el antiguo concepto de la miel como esencia sagrada de los dioses regalada a los mortales en la Edad de Oro; así la trata Virgilio en su conocida Geórgica $I V$, dedicada simbólicamente, como se sabe, a describir la cría de las abejas y la producción de la miel. La miel es "aérea" y "don celestial" en esta Geórgica, que empieza así: "Protinus aërii mellis caelestia dona / exsequar..." Por su afán de cuidar la "gloria mellis", puede creerse que las abejas han recibido una porción de la inteligencia divina: "His quidam signis atque haec exempla secuti / esse apibus partem divinae mentís et haustus /

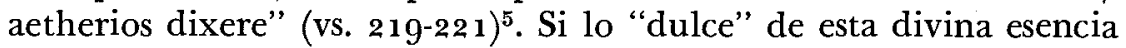
reaparece, según creo, en el pastor Melibeo, y después en el Meliseo de Sannazaro, para señalar ahora el carácter "dulce" del hombre

ironía- una Bitrubia a base del famoso arquitecto romano Vitruvius (p. 35) y una Polivia a base de Polibius (p. 114). El sentido de Meliboeus en la Antigüedad tardía ya no era claro: en la "Appendix" de Servio, un comentador no vacila en interpretarlo de este modo: "Meliboeus id est qui bovum curam gerat...", basándose en $\mu \epsilon ́ \lambda \epsilon \iota \nu$ ßov̂s (ed. Thilo, Lipsiae, 1902, ooo. fase. II, 16), explicación que repite un lexicógrafo moderno (GuTierre Tibón, Diccionario de nombres propios, México, 1956) y que, aplicada al Melibeo de Virgilio, resulta bastante inverosímil, puesto que él es decidida y casi exclusivamente un "pastor de cabras" (cf. Ecl. I, 12, 74; VII, 9); sólo una vez, de manera accidental, se le asocia con animales como "bueyes" ( $E c l$. VII, 11: "huc ipsi potum venient per prata iuvenci"). Tanto Calpurnio (I, 94; IV, 6 al.) como Nemesiano (I, 6 al.) tomaron de Virgilio el nombre de Melibeo. Carolus WENDEL, "De nominibus bucolicis", Jahrbücher für classische Philologie (Fleckeisens Jahrbücher), 26, Suppl. (1901), 1-go, afirma que Virgilio debió tomar su nombre de un pastor Meliboios en la leyenda de Edipo: "Quis hoc nomen fabulae adiecerit ignoramus; dubitari autem non potest, quin Vergilium in litteris omnino non inveniuntur" (p. 49). Véase también CarL RoberT, Oidipus, Geschichte eines poetischen Stoffs im griechischen Altertum, Berlín, 1915, t. 1, p. 75 y t. 2, p. 31. Pero si el sentido del nombre fue problemático en la tardía Antigüedad, no lo fue tanto para la edad moderna, la cual -desde Rojas- lo asoció con mel- 'dulce'. Así Covarrubias: Melibea 'dulçura de la vida', basándose en $\mu$ é $\lambda$ y en Bíos. Hay otros Melibeos en Gil Polo (ed. Madrid, 1953, p. 73), en la Arcadia de Lope (Obras escogidas, Madrid, 1953, p. 1133a) y en Bernardo de Balbuena (Siglo de oro..., Madrid, 1821, p. 72), y, finalmente, un burlesco Don Melibeo, "caballero y ridículo amante", en Salas Barbadillo, La estafeta del dios Momo (ed. Madrid, 1627), fol. 139r (en el siglo barroco, los motivos clásicos se tornan paródicos; cf. infra, nota 26).

5 Así, Cervantes, jugando con el nombre de la dama, puede llamarla "dulcísima Dulcinea" en la carta que le dirige Don Quijote (I, 25; t. 2, p. 277), a la vez que aplica el mismo superlativo a la actividad de las abejas - "dulcisimo trabajo"- en el discurso sobre la Edad de Oro (I, 11; t. 1, 317), que sin duda es lejana reminiscencia de Virgilio; el socarrón de Sancho, hablando de aquella carta y aludiendo al mismo matiz del nombre, sabrá decir: "...con cuya respuesta dulce y melificada volveré por los aires como un brujo"; Don Quijote repite la fórmula al final de la Primera parte: "dulcísima Dulcinea" (I, 52; t. 3 , p. 419). Ya veremos más adelante que el superlativo de dulce es epíteto que se aplica muy a menudo a la Virgen María, la cual entra también en la elaboración de la dama de Don Quijote. 
de la Edad de Oro, es muy natural que otros pastores renacentistas reciban nombres análogos, dotados del mismo mensaje, como el Meliseo de la Galatea de Cervantes, una Melisea en la Diana enamorada de Gaspar Gil Polo (ed. Madrid, 1953, p. 219) y tal vez el Melancio del Siglo de oro en las selvas de Erifile de Bernardo de Balbuena $^{6}$. También es natural que el concepto se extendiera a otros nombres afines: Nectalvo en Los pastores de Belén de Lope de Vega y Delicio en Balbuena (p. xiii), a la vez que se aplicaba a personajes no pastoriles, como el Dulcido del Patrañuelo de Juan Timoneda (ed. Madrid, 1949, p. 186). La transferencia del Dulcineo "pastoril" a la Dulcinea "dramática" o "novelística" equivale a la transferencia del Melibeo "pastoril" a la Melibea "dramática" de Fernando de Rojas (lo "dulce" ideológico del hombre de la Edad de Oro extendido a lo "dulce" tradicional de la mujer)?

${ }_{6}^{6}$ Ed. cit., p. 8. Debe de ser el mismo Melancio, pastor de Odiseo (XXII, 475) mencionado por Teócrito (Idilio $V, 150$ ). Su nombre deriva sin duda de la flor melanthium, la cual tal vez sugiriera al Renacimiento una asociación con mel- 'dulce'.

7 La onomástica pastoril tiene cuatro grandes categorías (dejando aparte, claro, muchas excepciones): $I$ ) nombres "vegetales" (los más numerosos): Florianos, Rosindas, Laureanos, etc.; 2) nombres de ninfas: Dóridas, Clóridas, Amarilis, etc.; 3) nombres con raíces que sugieren la belleza humana: Clarindas, Belisardas, Clarenios, etc.; y 4) nombres alusivos a la bondad del carácter humano en la Edad de Oro, categoría a la cual pertenece nuestro Dulcineo. He aquí una breve historia de esta última clase: Pacifico en L'Ameto de Boccaccio; el ya mencionado Meliseo de Sannazaro y el Meliso de Cervantes; los nombres en dulce arriba indicados; el Sincero de Sannazaro y también el Carino; Lealdo en la Arcadia de Lope de Vega; los muchos en Fid-, como Fidessa y Fidelia en la Faerie Queene de Spencer y el célebre Pastor Fido de Guarini (Fidelio muchas veces en el teatro de Lope, tal vez por inspiración italiana, y su último avatar, el Fidelio de Beethoven, que alude a la fidelidad conyugal); Fineldo en Los pastores de Belén; Finardo en La Cintia de Aranjuez de Gabriel de Corral (ed. Madrid, 1945, p. 58). Más significativos, y como síntesis de todos los demás, son los muchos en Cris- 'oro', que expresan el verdadero "carácter de oro" del hombre de la Edad Dorada: Crisaldo en Sannazaro (el cual introduce en la Europa del Renacimiento muchos de los nombres citados aqui); Crisalvo y Crisio en la Galatea, y ahí mismo Grisaldo, en su forma italiana, como el Grisóstomo del Quijote; Criseo, Crisalo y Crisalda en la Arca. dia de Lope. $\mathrm{Y}$ en otros géneros (que toman su onomástica de la novela pastoril, nodriza de toda literatura), tenemos la Crisolora de Timoneda (ed. cit., p. 149); Criselio y Criselia en Tirso de Molina (Ventura te dé Dios, hijo, y La mujer que manda en casa). El concepto desciende sin duda del chryseon genos de Hesíodo, a través de la aurea proles de Ovidio y de la gens aurea de Virgilio; cf. Inez S. Ryberg, "Vergil's Golden Age", Amer. Philol. Assoc. Trans. and Proceed., 89 (1958), 112-131. Luciano nos aclara el concepto con típica ironía en sus Saturnalia: "Todo en aquella edad brotaba sin siembra y sin arado; la tierra no daba espigas, sino panes y carnes adobadas; corría el vino en arroyos y las fuentes manaban miel y leche; todos eran buenos y áureos". Y más abajo: "aquellos hombres de oro macizo..." (Obras completas de Luciano, trad. F. Baráibar y Zumárraga, Madrid, 1890 , t. 4, pp. 298, 239). 
Fijándose en el célebre pasaje del primer capítulo del Quijote, Rafael Lapesa observa, en un penetrante artículo, cierto "nexo" entre los dos nombres de la dama: el grandilocuente inventado y el propio humilde. He aquí el pasaje:

Llamábase Aldonza Lorenzo, y a ésta le pareció ser buen título de señora de sus pensamientos; y buscándole nombre que no desdijese mucho del suyo y que tirase y encaminase al de princesa y gran señora, vino a llamarla Dulcinea del Toboso, porque era natural de Toboso: nombre, a su parecer, músico y peregrino, y significativo, como todos los demás que a él y a sus cosas había puesto ${ }^{8}$.

Así termina el primer capítulo. El distinguido erudito español cree que suyo, en la frase "no desdijese mucho del suyo", se refiere al nombre Aldonza. A mí me parece no sólo más probable, sino casi seguro, que aluda al nombre de Don Quijote mismo, ya que éste había pasado los ocho días precedentes creando tan peregrino y significativo nombre. Y aunque Cervantes haya querido sugerir la conexión entre Dulcinea y Aldonza, el pasaje sería en general irónico, y Dulcinea sí desdice, y mucho, de su rústica contraparte. Más importante, pues, que el "nexo" entre lo "dulce" de Aldonza y Dulcinea es la abierta oposición entre los dos nombres. Con la muy rústica Aldonza contrapuesta a la muy poética Dulcinea, Cervantes establece

8 "El autor del Quijote -dice Lapesa- identificaba Aldonza con Dulce. Dulcinea no está formado directamente sobre Aldonza, sino sobre el equivalente Dulce" ("Aldonza-Dulce-Dulcinea", BBMP, 23, 1947, p. 52). Añade Lapesa: "Mientras Casildea sólo modifica el final de Casilda, en Dulcinea se interpone un incremento -in-entre el nombre primitivo y la terminación. Es que Dulcea era inadmisible por excesivamente apegado al adjetivo dulce, y tal vez por el riesgo de evocar la serie jalea, gragea, oblea; no se encaminaba a nombre de "princesa y gran señora»; no resultaba tampoco «músico» ni «peregrino», contra lo que de seaba Don Quijote... El nombre de Dulcinea, sugerido por la reminiscencia de una obra ridicula [la de Lofrasso], debió conservar en la mente de Cervantes un matiz estimativo de ese origen"' (pp. 52-53). Como observa Lapesa (p. $4^{8}$ ), fue Clemencín el primero que hizo notar la conexión entre los dos nombres. Aun que hubo un nombre propio Dulce - a la documentación de Lapesa añádase el artículo de E. García Gómez, "Dulce, mártir mozárabe de comienzos del siglo x", AlAn, 19 (1954), 451-454-, no creo que sea necesario suponer la presencia del antropónimo Dulce en la formación de Dulcinea (basado, a mi ver, en latín dulc- +ineus, -inea). Sí es, en cambio, evidente que aquél se asociaba con Aldonza en la Edad Media y aun durante los siglos xvi y xvn: Dulce aparece junto a. Aldonza en varios textos, aplicado a la misma persona (cf. nota siguiente).

9 Nexo que sí parece existir en la mente de Cervantes. Cf. II, 14: "una tal Dulcinea del Toboso, llamada un tiempo Aldonza Lorenzo; como la mía, que, por llamarse Casilda y ser de la Andalucia, yo la llamo Casildea de Vandalia": (t." 4, p. 299). La falsa etimología que Covarrubias da de Aldonza (ár. $a l+d u l c e)$ era común en la época. 
desde el principio su dicotomía "historia-poesia", pues no hay ningún nombre tan "histórico" como Aldonzal0. Lapesa señala la verdadera alcurnia visigótica (Aldegundia) del nombre, y a ese largo entronque tradicional y medieval (cf. nota 10) se deberá que el viejo nombre aflorara en tiempos de Cervantes como el prototipo de nombre ínfimo y rústico. También la madre de Dulcinea es Aldonza (de apellido Nogales: I, 25; t. 2, p. 269), y el nombre se asocia a menudo con otros nombres rústicos. Sancho, al enterarse por primera vez de la identidad "histórica" de la dama, juega con el contraste entre los nombres: “Ta, ta. . ¿que la hija de Lorenzo Corchuelo es la señora Dulcinea del Toboso, llamada por otro nombre Aldonza Lorenzo"? (loe. cit.), e inmerso en su visión "histórica", casi se olvida de la invención poética: ". . . a la señora Aldonza Lorenzo, digo a la señora Dulcinea del Toboso" (ibid.). Como sabemos, Aldonza es "moza de chapa, hecha y derecha, y de pelo en pecho". Tan hondo es el carácter rústico del nombre, que Quevedo, siguiendo la técnica del Lazarillo en su agresión total contra los linajes caballerescos y aristocráticos, combina precisamente el nombre de Aldonza con los otros nombres "super-cristianos" (es decir, "ínfimos y falsos") de cristianos nuevos en el Buscón. Si el autor del Lazarillo llama a los padres del protagonista, valiéndose calculadamente de la inmemorial onomástica rústica, "Thomé Gonçales" y "Antona Pérez", Quevedo, por su parte, refuerza y, por decirlo así, "maximiza" el proceso: los padres de Pablos son Clemente Pablo y Aldonza de San Pedro, la cual es hija de Diego de San Juan y nieta de Andrés de San Cristóbal ${ }^{11}$. La alcurnia de la dama de

10 "Dulcinea es la idea pura; a esta idea se llega partiendo de la realidad; pero no es la realidad observable, es la realidad del refranero. Aldonza Lorenzo es la heroína del folklore, que tanto ha contribuido también a formar a San. cho: "Aldonza, con perdón», "Aldonza sois, sin vergüenza», "Moza por moza, buena es Aldonza". Dulcinea no existe, pero Aldonza es una abstracción. En el siglo xviı, esta relación Dulcinea-Aldonza debió ser uno de los rasgos burlescos que más excitarian a risa..." (Joaquín Casalduero, Sentido y forma del "Quijote", Madrid, 1947, p. 48).

11 Unamuno se sorprendió de la ausencia de linaje del héroe al principio del relato cervantino: "Nada sabemos del nacimiento de Don Quijote... Se ha perdido toda memoria de su linaje, nacimiento, niñez y mocedad..." (Vida de Don Quijote y Sancho, Madrid, 1914, p. 31). J. Casalduero ha dicho que "el autor quiere presentarnos a un ser lo más antiheroico posible y lo más opuesto a los caballeros andantes... Lo que a Cervantes no importa es lo que han tenido sumo interés en decirnos todos los autores de caballerías" ("Explicando la primera frase del Quijote", BHi, 36, 1934, pp. 146, 147; cf. María Rosa Lida, "De cuyo nombre no quiero acordarme", $R F H$, 1, 1939, p. 170). Pero el "ser lo más antiheroico posible" y el "más opuesto a los caballeros andantes" no es Don Quijote, sino el pícaro, como arriba apuntamos. La "falta" de genealogía es ciertamente más piadosa que la abierta agresión anti-* genealógica de la picaresca. Don Quijote, por lo demás, ofrece una pseudogenealogía burlesca en I, 21: "... yo soy hijodalgo de solar conocido, de pose- 
Cervantes es clara: Dulcinea es la "poesía" y Aldonza la "historia" del caso.

Quizá a esto se deba en parte el que muy raramente vaya acompañado el nombre de Dulcinea de Doña, a pesar de las innumerables "doñas" del mundo medieval, y a pesar del permanente Don de su señor"12. Si Sancho critica a Sansón Carrasco por decir "Doña Dulcinea" - "Nunca... he oído llamar con Don a mi señora Dulci-

sión y propiedad, y de devengar quinientos sueldos; y podría ser que el sabio que escribiese $\mathrm{mi}$ historia deslindase de tal manera mi parentela y descendencia, que me hallase quinto o sexto nieto de rey" (t. 2, pp. 149-150).

12 Por supuesto, el Don de Don Quijote no es título de hidalgo de aldea, sino Don "caballeresco", y el héroe lo abandona en cuanto recobra la cordura, al final de la obra: “... ya yo no soy Don Quijote de la Mancha, sino Alonso Quijano" (II, 74; t. 8, p. 253). Y sin embargo, es posible que en ese Don influyera -aunque oblicuamente- el uso ilegítimo del título en muchos hidalgos empobrecidos, tema que fue a menudo objeto de parodia en los siglos xvi y xvn; se trataría de un elemento más de parodia "no caballeresca" en el Quijote. Cf. John C. Dowling, "A title of distinction", $H, 4^{1}$ (1958), 449-456 (el mejor estudio sobre el tema). Según Rodríguez Marín (t. 4, p. 84), el Doña aparece dos veces en la Primera parte (capítulos 8 y 9); la primera vez se usa para equiparar la "nobleza caballeresca" de Dulcinea con la de su señor, paralelismo onomástico en general eludido por Cervantes: “... sabed que yo me llamo Don Quijote de la Mancha, caballero andante y aventurero, y cautivo de la sin par y hermosa Doña Dulcinea del Toboso". Aunque el indice de Bowle sólo registra tres apariciones de "Doña Dulcinea" en la Segunda parte, de hecho hay más: una en boca de Don Quijote (II, 9; t. 4, p. 202), otra, irónicamente, en la del Duque (II, 3o; t. 5, p. 314), otra también irónica en boca de Sansón (II, 3 ; t. 4 , p. 84). Y varias otras veces es Sancho quien usa el Doña, relacionándolo curiosamente con el tema de los azotes y con el del desencanto de Dulcinea: "lo del encanto de mi señora Doña Dulcinea" (II, 33; t. 6, p. 71); "Pero querría yo saber de la señora mi señora Doña Dulcinea del Toboso adónde aprendió el modo de rogar que tiene" (II, 35; t. 6, p. 121); “...porque venía a dar orden [Montesinos] de que la señora Doña Dulcinea del Toboso se desencantase" (t. 6, p. 124); "yo procuraré salir de la deuda... por que goce el mundo de la hermosura de la señora Doña Dulcinea del Toboso" (t. 6, p. 125). Y luego, en el capítulo último del libro, estando Don Quijote en el lecho de la muerte: "quizá tras de alguna mata hallaremos a la señora Doña Dulcinea desencantada..." (II, 74; t. 8, p. 257). No es del todo claro por qué Sancho usa el Doña así; tal vez sólo por simpleza, o a causa del respeto que siente el rústico por una dama de alto rango; es decir, del respeto que le tendría a "Dulcinea" si existiera, O bien, porque no comparte la visión caballeresca de su amo, quien casi siempre dice: "señora". Obsérvese que, salvo unas cuantas reinas, como "Doña Beta" en el Guillermo de Inglaterra o "Doña Ginebra" en Peregrino y Ginebra, las heroínas de las novelas caballerescas no llevan nunca el Doña. Quizá sea porque, como dijo Clemencín (t. 4, p. 53), "el tratamiento de Don lleva siempre consigo cierto sello o idea de gravedad que no asienta bien en un sujeto que todo es ternura, suavidad y gracias"; o quizá se deba a la juventud y al estado de soltera de la dama caballeresca: Doña pudo haberse identificado con dueña, designación de la mujer casada y ma" dura (en contraste con doncella 'mujer joven y soltera'). He ahí un problema por resolver. Notemos de paso que en una parodia rigurosa de las novelas caballerescas, la "Doña Tolosa" y la "Doña Molinera" del capítulo 3 de la 
nea, sino solamente la señora Dulcinea del Toboso, y ya en esto anda errada la historia"'13_, es simplemente para cumplir su función de esclarecer la verdad "histórica" de las cosas, y al mismo tiempo para decir que el título no cuadra con un nombre tan altamente renacentista y pastoril ${ }^{14}$. Es verdad que también la atmósfera caballeresca - sin duda con mucha mayor eficacia- contribuye a que llamen generalmente a Dulcinea "señora", como dice Sancho; pero en lo referente al nombre en sí, la parodia ha llegado lejos. Ese mundo caballeresco, tan burlesca pero evidentemente presentado en el nombre Don Quijote, sin olvidar una posible reminiscencia de Lanzarote, como dice Spitzer ${ }^{15}$, está del todo ausente del nombre Dulcinea, "persona", por lo demás, tan pasiva y desnatura-

Primera parte deberían haberse llamado "intanta" o aỉgo así: nuevamente vemos que Cervantes piensa más en la realidad contemporánea que en el modelo caballeresco.

13 Es el capítulo 3 de la Segunda parte, donde está el famoso debate sobre "historia y poesía", estudiado tan genialmente por Toffanin y Américo Castro. Sansón Carrasco comenta que "no es objeción de importancia ésa", y Don Quijote replica: "No, por cierto" (t. 4, p. 84). Y es verdad, desde el punto de vista "poético". Pero Sancho no aguanta casi nunca la "poetización" de la realidad, y por eso tiene que enmendarle la plana a Sansón y defender la verdad "histórica" de las cosas.

14 Los editores del reciente estudio Los nombres de personajes en las comedias de Lope de Vega (Berkeley y Los Angeles, California, 1961), S. G. Morley y R. W. Tyler, observan: "Es de notar que ciertos nombres de pila no llevan, según el uso de Lope, el "Don» o "Doña» calificativo, aunque denotan claramente caballeros y damas" (Introducción, t. 1, p. 24). Enumeran unos 50 nombres que aparecen en Lope sin Don ni Doña, los más de ellos pastoriles y casi todos "clasicistas": Albano, Andronio, Aurelio, Belardo, Camilo, Celio, Ergasto (en Sannazaro y otros muchos), Feliciano, Felicio, Fineo, Fulgencio, Laurencio, Leonelo, Lisandro, Liseno, Liseo, Lucindo, Marcelo, Octavio, Riselo, Belisa, Camila, Celia, Clarinda, Clavela, Diana, Elisa, Fabia, Feliciana, Felisarda, Finea, Flora, Florela, Isabela (la forma "italiana", claro), Leonarda, Lucinda, Octavia, Rosela, Silvia, etc. Y los editores añaden: "Algún motivo debe de haber para semejante discrepancia entre estos nombres y otros como Diego, Enrique, Juan, Rodrigo; Juana, Isabel, Sol, y muchos más; pero hasta ahora se nos escapa el secreto". Pero el motivo es claro. El Don tiene demasiadas asociaciones medievales y castizas para juntarse con los nombres de la nueva aristocracia literaria. Montemayor no da nunca el título a Diana, y el único que lo lleva en el libro es don Felis, porque Felis es el castizo Félix, a pesar del antietimológico cambio consonántico, cuya finalidad parece ser la adaptación al uso pastoril, tal vez sobre el modelo de Filis o Amarilis. Doña Dulcinea no suena, ni tampoco Doña Diana, u otros nombres semejantes.

15 Debemos recordar aquí el penetrante estudio de DÁmaso Alonso, "E1 hidalgo Camilote y el hidalgo don Quijote", $R F E$, 20 (1933), 391-397, sobre la posible influencia del carácter y el nombre de Camilote (personaje del Pri. maleón y de su imitación, el Don Duardos de Gil Vicente) sobre la persona y el nombre de Don Quijote. Todo puede ser. Cabe observar también que el nombre del ridículo hidalgo Camilote tiene una curiosa semejanza con un importante topónimo de las leyendas artúricas, escrito en español Camaloc, Camalot, topónimo que, sin embargo, aparece mencionado en muy pocos libros 
lizada (pastoril y platónicamente) como eran activas y sensuales sus predecesoras Oriana y Carmesina ${ }^{16}$.

Evidentemente tuvo razón Lapesa al asociar el proceso de la formación de Dulcinea con el de Casildea: "Dulcinea será respecto a Dulce lo que la Casildea del Caballero de los Espejos es respecto a Casilda..." (art. cit., p. 48). Ambas son formas pastoriles, y es posible que provinieran conjuntamente de reminiscencias del genial sardo, creador de Dulcineo. Viene poco al caso el que Cervantes en el Quijote y en el Viaje del Parnaso haga de Lofrasso objeto especial de burla, ya que él, como el autor del Lazarillo en su prólogo, y como todos los poetas del Renacimiento, se adhiere firmemente a la famosa máxima atribuida a Plinio: "dicere etiam solebat nullum esse librum tam malum, ut non aliqua parte prodesset". Y resulta que el sardo es el maestro de todos en materia onomástica. Dulcineo es suyo, y también Dulcino, Dulcina y Dulçanio, todos con un sentido del "carácter dulce" del hombre pastoril. Creó además una larga serie de nombres en -dea, todos ellos, sospecho, con una sugerencia de diosa (a base del latín o del italiano dea), además de que lucen el prestigioso sufijo - ea. Se vale de los principales moldes pastoriles: Clori- (de Chloris, diosa de las flores) y Dori-(de Doris) para su Cloridea (t. 1, p. 167) ${ }^{17}$ y su Doridea (t. 1, p. 44), y luego, entusiasmado al parecer con su invención, se lanzó también a crear una Claridea (t. 2, p. 47) ${ }^{18}$, una Belidea (t. 1, p. 168), una Hidea

de caballerías españoles. De los enumerados infra, en el Apéndice, sólo figura en el Baladro del sabio Merlin (Camaloc: NBAE, t. 6, p. 69a), en La demanda del Santo Grial (Camaloc: ibid., p. 163a), en el Tristán de Leonis (Camalot: ibid., p. 369a), y en el Clarián de Landanis, III (Toledo, 1524, fol. xciir), todos ellos, salvo el Clarián (?), de puro abolengo "bretón". Lo escaso de su aparición es tal vez indicio del poco conocimiento directo que Cervantes (y, añado yo, los demás autores españoles) tenían de la leyenda artúrica, según afirmó William J. EnTwistle, The Arthurian legend in the literature of the Spanish Peninsula, London, 1925, pp. 213-214 y 250. Ese sitio, residencia principal del rey Artús, se menciona muy a menudo en los libros caballerescos franceses, bajo las formas Camaelot, Camaeloc, Camelot, etc. (Véase Louts-Fernand FluTRE, Table des noms propres... dans les romans du moyen âge, Poitiers, 1962).

${ }^{16}$ Las damas caballerescas no son "dulces", al menos en una serie representativa de libros de caballerias: Amadis de Gaula, Palmerin de Inglaterra, Lepolemo y Amadís de Grecia; ni apenas lo son más sus hermanas, las damas de los poetas de los cancioneros del xv, como veremos en el Apéndice. La dama "dulce" por excelencia de la tradición medieval española es la Virgen.

${ }_{1 \tau}$ Cito a Lofrasso por la edición en dos tomos de Londres, 1740.

18 Los nombres en clar, por su capacidad de sugerir la belleza plástica del hombre renacentista, son frecuentísimos en la novela pastoril, como en toda la literatura del Renacimiento. Es de notar que la misma Cariclea de Heliodoro se convirtió en Clariquea, probablemente no por mera "metátesis", como dice F. López Estrada (ed. de Los amores de Teágenes y Clariquea, Madrid, 1954, p. xxxii), sino para adaptarse al modelo de los popularísimos nombres en Clar-. Estos nombres, por cierto, no eran del todo desconocidos en la Edad 
(t. 2, p. 57) y, camino ya al absurdo, llegó a forjar incluso una Archidea $\left(\mathrm{t} 1 \text {, p. } 5^{1}\right)^{19}$.

Pero lo más importante no es, claro está, el hecho de hallar al gran autor imitando a otro escritor, sino el de verle seguir a un autor pastoril y conocido. En realidad, la especial mofa que hace Cervantes de Lofrasso es indicio seguro de la impresión que le causó. (Creo discernir en Cervantes un gesto de cariño para el extravagante sardo, "colega" suyo, cuyo libro "puso aparte" el Cura "con grandísimo gusto" en el escrutinio). Recordemos de nuevo la vieja preocupación bucólica de Cervantes y la marcada huella que esta preocupación dejó en su obra máxima. En Cervantes, la transferencia de Dulcineo a Dulcinea no es tan completa como la del Melibeo virgiliano a la Melibea de Rojas, y la dama, nombrada pastorilmente al principio, siempre guarda algo de esa primitiva configuración. Vemos en el mismo capítulo 25 de la Primera parte (capítulo clave para la comprensión de la elaboración literaria de Dulcinea) cómo Don Quijote explica claramente el matiz "idea pura" de la dama, roncepto que recientemente ha hecho resaltar Joaquín Casalduero:

... así que, Sancho, por lo que yo quiero a Dulcinea del Toboso, tanto vale como la más alta princesa de la tierra. Si, que no todos los poetas que alaban damas debajo de un nombre que ellos a su albedrio les ponen es verdad que las tienen. ¿Piensas tú que las Amarilis, las Filis, las Silvias, las Dianas, las Galateas y otras tales de que los libros ["pastoriles", agreguemos], los romances, las tiendas de los barberos, los teatros de las comedias están llenos, fueron verdaderamente damas de carne y hueso, y de aquellos que las celebran y celebraron? No por cierto, sino que las más se las fingen por dar sujeto a sus versos, y porque los tengan por enamorados y por hombres que tienen valor para serlo; y así bástame a

Media, como lo demuestran los célebres Conde Claros y Claraniña del Romancero.

19 Si Cervantes se llama a sí mismo "raro inventor", quién sabe si no consideraba también "raro" al sardo en la invención de nombres, pues éste tiene la más "rara" inventiva de todos en materia onomástica; no imitaba a sus predecesores, como los demás autores pastoriles, sino que se esforzaba siempre en ser original, hasta llegar a veces a lo estrambótico. El sufijo -eo, -ea es más frecuente en él que en ningún otro autor (¿debido a su lengua materna?): además de los nombres en -dea, tiene Solineo (t. 1, p. 305), Seliceo (t. 2, p. 47), Montineo (t. 2, p. 63; Sannazaro creó el famoso Montano, frecuente después de él), Florineo (t. 1, p. 9), Cormineo (t. 2, p. 285), Beliseo (t. 1, p. 229), Belinea (t. 2, p. 63), Claudinea (t. 1, p. 273) y Arborea (t. 2, p. 71). Al parecer, se introduce a sí mismo tres veces con los nombres de Fraxineo (t. 2, p. 277), Frexineo (t. 2, p. 52) y Frexano (t. 1, p. 1), hechos a base del nombre de uno de los árboles más mencionados en los poemas pastoriles de Virgilio. Algunos nombres lofrassianos debieron de hacerle gracia a Cervantes, como por ejemplo un pastor Sierradoro (t. 1, p. go), o una ninfa Timidona (t. 2, p. 9). Tiene Lofrasso en total 84 nombres de pastores, los más invenciones suyas. 
mí pensar y creer que la buena de Aldonza Lorenzo es hermosa y honesta; y lo del linaje importa poco... (t. 2, pp. 273-275).

Típica mezcla multifacética cervantina: negación de la existencia física de las damas, atribución del nombre y carácter de éstas a simples necesidades literarias, todo ello unido, quizá, a una ligera mofa erasmiana de ios linajes. Ahora bien, dentro de toda la complicada serie de atributos concedidos a la dama figura en lugar prominente el poético-pastoril, y Cervantes utiliza la misma onomástica pastoril que ha ofrecido a todos los poetas del Renacimiento, bucólicos o no, nombres bellos y de corte clásico para sus damas. Sumergido tal vez en recuerdos de sus propios orígenes pastoriles, así como en la corriente general de su tiempo, y quizá con una pirandeliana reminiscencia de su propia Galatea (como durante el escrutinio de la biblioteca), llega a insinuar que Don Quijote nombra a su señora como los otros autores pastoriles a las suyas, y que la hace irreal ("pintola en mi imaginación como la deseo", ibid.), según hace cualquier poeta con su Filis o su Amarili ("pastoras", naturalmente). Casi lo mismo dirá en su "Adjunta al Parnaso": "el más pobre poeta del mundo... puede decir que es enamorado, aunque no lo esté, y poner el nombre a su dama como más le viniere a cuento, ora llamándola Amarili, ora Clori, ora Filis, ora Fílida..."

Pero Cervantes es aún más explícito al hablar sobre la naturaleza del nombre Dulcinea en la Segunda parte, donde Don Quijote, desengañado y desalentado después de su derrota a manos del $\mathrm{Ca}$ ballero de la Blanca Luna, decide volverse hacia otro mundo ideal, el pastoril. Todos necesitarán nombres pastoriles ${ }^{20}$, menos Dulcinea, y así es como el concepto "Dulcinea" se reconcentra al fin y recobra su prístina y total realidad. El caballero se expresa así: "Las pastoras de quien hemos de ser amantes, como entre peras podremos escoger sus nombres; y pues el de mi señora cuadra asi al de pastora como al de princesa, no hay para qué cansarme en buscar otro que

20 "El nombre propio siempre ha sido considerado índice de orientación vital, y un cambio en ésta repercutirá en aquél... Así lo entiende nuestro héroe, cuyas distintas vivencias se han ido cristalizando en una verdadera revolución onomástica: Alonso Quejana-Don Quijote de la Mancha-Caballero de la Triste Figura-Caballero de los Leones, etc. Ahora llega el momento de reorientar su vida, abandonar su vieja personalidad, dejar un mundo y entrar en otro. Todo esto se refleja en el acto de auto-bautismo: Don Quijote voluntariamente se convierte en el pastor Quijotiz. Con rigor y método se prosigue esta creación $a b$ initio: Sancho será ahora el pastor Pancino, Sansón Carrasco el pastor Carrascón, el barbero Miculoso, el cura Curiambro, etc. El mundo pastoril recién creado rápidamente se torna hermético, como denotan no sólo estas personalidades desprendidas de sus encarnaciones previas, sino también la propia naturaleza, desasida de su realidad por el continuo uso de superlativos. En suma, Don Quijote ha efectuado una pastorilización uniforme y absoluta" (Juan Bautista Avalle-Arce, La novela pastoril española, Madrid, 1959, pp. 228-229). 
mejor le venga" (II, 67; t. 8, p. 159). Y en el capítulo 73, replicando a Sansón Carrasco cuando éste vuelve a afirmar la necesidad de escoger nombres para sus pastoras: "Eso está de molde - respondió Don Quijote-, puesto que yo estoy libre de buscar nombre fingido, pues está ahí la sin par Dulcinea del Toboso, gloria de estas riberas, adorno de estos prados, sustento de la hermosura, nata de los donaires" (t. 8, p. 244).

Fijémonos bien: al entrar en otro mundo ideal -exhausta ya la vía caballeresca después de su rendición al Caballero de la Blanca Luna-, hay que orientar primero la acción hacia la creación de nombres propios, igual que en el capítulo primero de la Primera parte. Resta ahora fijar la total identidad onomástica de la dama. La expresión "sin par" es caballeresca (del Amadis, I, 4: Oriana, "la más hermosa criatura que nunca se vio; tanto, que ésta fue la que Sin-par se llamó, porque en su tiempo ninguna hubo que igual le fuese"), y refleja el concepto idolátrico cortesano de la mujer"1; el "del Toboso" (caballeresco burlesco) es concesión al "de la Mancha" de su señor 22 ; en cambio, "gloria de estas riberas" y "adorno de estos prados" son epítetos de pura cepa pastori123.

${ }^{21}$ Lo de "sin par" es, sin embargo, lo más asimilable al carácter pastoril, a pesar del claro origen caballeresco que en ese epíteto hallaría Cervantes. La misma mezcla aparece en el pseudónimo pastoril de la poetisa inglesa Catherine Fowler Philips, de mediados del siglo xvn, que adopta el nombre "The Matchless ['Sin-par'] Orinda", y da otros nombres pastoriles a una serie de amigos suyos: Cratander, Palaemon (de Virgilio), Poliarchus, Valeria, Celimena, Polycrite, Ardelia, Philoclea, Regina, Rosania, Philaster, Phillis, y hasta una Pastora a secas (cf. Philip Webster Souers, The Matchless Orinda, Cambridge, Mass., 1931, pp. 44-45). La Sra. Philips debió de tomar su apodo de Tasso, su autor predilecto (pp. 142-143), pues éste tiene un Orindo ("pagano") en su Gerusalemme liberata (1581); el nombre pasó también a la novela pastoril española: lo utiliza Luis Gálvez de Montalvo en El pastor de Filida (1582; ed. Valencia, 1792, p. 181) asociándolo, sin duda, con ese "carácter de oro" de que hablamos en la nota 7. Orinda reaparece como nombre de un pueblo en California, cerca de San Francisco.

${ }^{22}$ A Tirso se le olvida, al parecer, la designación "del Toboso": "¿Sois la Infanta... / a lo nuevo quijotil / Dulcinea de la Mancha?" (Amor por señas, II; cit. por J. E. Hartzenbusch, Las 1633 notas..., Barcelona, 1874 , p. 178b). Aunque esporádicamente aparece con designación de lugar el nombre de la dama caballeresca - Pandricia de Lacedemonia, Polinarda de Grecia (muy raro así), Fidelia de Lacedemonia, en el Palmerin; Elisena de Gaula, reina, en el Amadis-, el topónimo es en general prerrogativa de los varones (reyes, príncipes o simples caballeros): Brian de Monjaste, Ismosil de Borgonña, Angriote de Estravaus, etc., en el Amadis. No hay, por ejemplo, ninguna Oriana de la Gran Bretaña, a pesar de ser ella princesa. Cervantes querrá dar a la dama un disparate geográfico semejante al que ha dado al caballero.

${ }^{23}$ Dice Rodríguez Marín (ed. cit., t. 8, p. 244): “...es muy propio del género pastoril nombrar las riberas en lugar de las tierras o comarcas. Casi todos los fingidos pastores son ribereños. Facilísimo sería citar ejemplos de ellos: sin salir de El Pastor de Fílida, de Gálvez de Montalvo, hailos a docenas". 
Dulcinea en sí, como nombre, se resiste a toda atribución caballeresca ${ }^{24}$, a menos que consideremos como tales los ideales trovadorescos introducidos por los poetas del siglo xvr, ellos mismos saturados ya de bucolismo renacentista. Pero todo es cuestión de cronología. Unido Dulcinea al "del Toboso", y fundido el nombre con la mujer-diosa del petrarquismo seiscentista -o sea con la tradición de las "dulces enemigas", ausente o muy escasa en los cancioneros del siglo xv, y tomada probablemente de Petrarca en el siglo $\mathrm{xvI}^{25}$-, ese nombre sirve para identificar a la engrandecida dama caballeresca que exige el relato. Si añadimos, finalmente, la actitud tradicional hacia la Virgen María, tantas veces nombrada "dulce" y "dulcísima", lo mismo en la Edad Media que en el Renacimiento, tendre-

${ }^{24} \mathrm{He}$ examinado unos treinta y cinco libros de caballerías y no encuentro un solo nombre formado a base de dulce, ni para varón ni para mujer; es de creer que pocos o ninguno se encontrarán en los demás. Enumero los siguientes que he podido ver (omito las ediciones, por no alargar la lista): Amadis de Gaula; Baladro del sabio Merlin; Belianis de Grecia; Lepolemo... Libro primero del Cavallero de la Cruz; Libro segundo del Cauallero de la Cruz; El Cavallero del Sol; Hystoria del Rey Canamor y del Infante Turian; La leyenda del Cavallero del Cisne; La hystoria del muy valiente... Clamades; El segundo libro del cavallero Clarián de Landanis; Libro tercero de Don Clarián; La demanda del Santo Grial; Enrique, Emperador de Constantinopla; Espejo de principes y cavalleros [Caballero del Febo], Primera parte; Las sergas... de Esplandian; Flores y Blancaflor; Felixmagno; ...Felixmarte de Yrcania; La corónica de... Don Florisel de Niquea; La destrucción de Jerusalem; ... la linda Magalona; Cuento del Enperador Carlos Maynes...; La linda Melosina; Olivante de Laura; Palmerin de Inglaterra, libro primero; Id., libro segundo; Palmerin de Oliva; ...Conde Partinuples; ...cauallero Platir; ... Olineros de Castilla y Artits Dalgarbe; ...Roberto el Diablo; Tablante de Ricamonte; Silues de la Selua; ...Tristán de Leonis.

25 Don Quijote mismo dice una vez a la italiana "la dulce mi enemiga" $(\mathrm{I}, 13)$, tomando la expresión de una traducción española ("De la dulce mi enemiga / hace un mal que el alma hiere") de cierto poema de Serafino Aquilano ("Dala dolce mia nimica"), cuya primera estrofa aparece intacta en boca de la dueña Dolorida en la Segunda parte (cap. 38). Rodríguez Marín estudia la tradición del poema de Aquilano en España (t. 6, pp. 164-165). "Dulce enemiga" se encuentra también tres veces en los versos de la Galatea (Obras completas, Madrid, 1946, pp. 691b, $713 b$ y $766 a$ ), como aparece asimismo la expresión concomitante "la bella ingrata mi enemiga" (p. $766 b$ ), repetida luego en la carta de Don Quijote (I, 25$)$ : " $O$ Oh bella ingrata, amada enemiga mía!" Ya veremos en el Apéndice que "dolce nemica", expresión predilecta de Petrarca, pasaría al siglo xvi español junto con otros muchísimos usos suyos de dulce. No será accidental, en verdad, que Covarrubias, al comentar el uso poético del adjetivo, recuerde precisamente un verso de Petrarca, "Mille fiate, o dolce mia guerrera", y el famoso de Garcilaso: "Flérida para mí dulce y sabrosa", dando a entender que, como hemos expuesto aquí, el concepto de la "dulce mujer" resulta de una confluencia de las dos corrientes, la petrarquesca y la pastoril. Caso raro es el superlativo "dulcíssima enemiga" de López Maldonado en su Cancionero (1586), fol. $78 \mathrm{v}$. Menéndez Pidal señala una remota aparición de la fórmula "ma douce ennemie" en el Tristín francés (Poesia juslaresca y juglares, Madrid, 1924, p. 179, nota). 
mos un nombre fundado sobre tres bases: su forma y gran parte de su espíritu es puramente pastoril, pero atrae hacia sí esencias del "dulce" de las "dulces enemigas" y otros usos semejantes de Petrarca, así como de la "dulzura" inmemorial de la Virgen (véase el Apéndice), tan vivamente representada en la dama de Don Quijote: "guía" y "norte" de su vida y conducta, "único refugio de [sus.] esperanzas"'26.

\section{APÉNDICE: LA "DULCE" MUJER EN LA HISTORIA}

El empleo del epíteto dulce en la Edad Media ha sido estudiado, entre otros, por WERner Armknecht, Geschichte des Wortes "süss", I. Teil: Bis zum Ausgang des Mittelalters, Berlin, $193^{6}$ (Germanische Studien, Heft 171), y, más recientemente, por S. Heinimann, "Dulcis: ein Beitrag zur lateinisch-romanischen Stilgeschichte des Mittelalters", $H D A$, t. 2, pp. 215-232. Como reconoce Heinimann, el uso de dulce en España

26 Al mismo tiempo, tiene razón Lapesa (aunque no creo que se deba al influjo de una "obra ridícula", sino a la tensión producida por una parte entre Dulcinea y Toboso, y por otra entre Dulcinea y Aldonza, que son en el fondo dos pares de igual disparidad) al decir que "en el complicado juego de proyecciones que se entrecruzaron en la creación del Quijote, el mismo Dulcinea hablaba, sí, de evasión elevadora hacia el reino de lo soñado; pero a la vez debía tener resonancias de comicidad" (art. cit., p. 53). Es cierto: la mera presencia de una aristocrática "pastora" (por el nombre, digo) al lado de Aldon$z a$ y, por otra parte, de "Emperatriz de la Mancha" (y otros atributos análogos), produce una tensión de absurdo, que se extiende a todos los otros absurdos relativos a la dama ("platónicos" o "caballerescos") que salen de la fantasía del caballero. Pero también eran tiempos en que se empezaba a ridiculizar lo pastoril, género cansado y que había llegado al punto de saturación, como antes el caballeresco (la última novela pastoril, Los pastores del Betis, de Gonzalo de Saavedra, es de 1633). Y los nombres pastoriles sirven de perfecto blanco de burla, como se ve a menudo en Cervantes mismo; repito: "Item, que el más pobre poeta del mundo... pueda decir que es enamorado, aunque no lo esté, y poner el nombre a su dama como más le viniere a cuento, ora llamándola Amarili, ora Anarda, ora Clori, ora Filis, ora Fílida" ("Adjunta al Parnaso", Viaje del Parnaso). La comicidad implícita en el Dulcinea cervantino se debe, no a Lofrasso, sino a la burla misma de todo el género pastoril. Nótese también el tono festivo e irónico del capítulo 73 (t. 8, p. 245), donde Sansón Carrasco comenta los nombres pastoriles citando casi los mismos que vimos en el capítulo 25 de la Primera parte: "Y cuando faltaren, darémosles los nombres de las estampadas e impresas, de quien está lleno el mundo: Fíliclas, Amarilis, Dianas, Fléridas, Galateas y Belisardas; que pues las venden en las plazas, bien las podemos comprar nosotros y tenerlas por nuestras. Si mi dama, o, por mejor decir, mi pastora, por ventura se llamare Ana, la celebraré debajo del nombre de Anarda; y si Francisca, la llamaré Francenia; y si Lucía, Lucinda, que todo se sale allá; y Sancho Panza, si es que ha de entrar en esta cofradía, podrá celebrar a su mujer Teresa Panza con nombre de $T e$ resaina". Y todo, en el fondo, encierra una burla ("barroca") de los temas clásicos. 
está por estudiar ${ }^{27}$. Las siguientes páginas sólo quieren ser apuntes para un estudio a fondo sobre el tema.

Durante la Edad Media el adjetivo dulce se usó en Europa fundamentalmente aplicado a Cristo y a la Virgen ${ }^{28}$. De manera secundaria, la idea de 'dulzura' se asoció también con otras figuras y aspectos de la religión. Para comprobarlo, basta hojear una colección representativa de la poesía medieval, The Oxford book of medieval Latin verse (Oxford, 1959): "Salve, regina misericordiae, / vita, dulcedo et spes nostra, salve! ( . . o clemens, o pia, / o dulcis Maria" (p. 196); "Dulcis Iesu memoria" (p. 347); "Iesus dulcedo cordium" (p. 348); "mundum replens dulcedine" (p. 349); "Hic amor ardet dulciter, / dulcescit mirabiliter" (p. 349); "Iesu sole serenior, et balsamo suavior, omni dulcore dulcior" (p. 352); "o dulcis! o pie! / o fili Mariae" (p. 44o); la Cruz dice: "dulce pondus sustineo, / dulcem fructum possideo" (p. $3^{87}$ ), etc. ${ }^{29}$

Armknecht (pp. 117 ss.) aduce otros muchos ejemplos: "spiritus dulcis", "cor dulcissimum", "de humanitatis Christi dulcissima memoria", "Maria plena dulcedine, plena omni suavitate", "summa dulcedo", "o dulcis divinitas", etc., etc., y observa: "Die Anwendung in dieser mystischen Literatur is ungemein reichhaltig". La literatura religiosa en lengua vulgar adopta el concepto de 'dulzura'. En Alemania: "der Gebrauch von süeze in der religiösen Sphäre ist damals so häufig und vielfach so formelhaft gewesen wie etwa die heutigen Verbindungen mit lieb, z.B. lieber Gott, lieber Freund" (p. 29). En Francia: "dulce gehörte auch neben benigne, debonnaire und amiable zu den gebräuchlischten Marienepitheten" (p. 115).

Del ámbito religioso el concepto pasa al profano, y dulce se convierte en epíteto de la mujer amada (cf. ArMknecht, passim, y Heinimann, pp. 221-222). El abrumador número de superlativos de dulce en los Carmina Burana (cf. nota 40) hace pensar que se trata de parodias deliberadas y blasfematorias del lenguaje devocional: Venus es "dulcissima" o también "dulcis prepotens amoris regina" (ed. Hilka und Schumann, Heidelberg, 1930-1941, t. 1, pte. 2, pp. 54, 5o); una muchacha es "puellula dulcis et suavissima" (p. 301), "dulcissima" (pp. 293, 311; cf. 277); un amante, "dulcissime" (p. 37). Dido llama a su hermana "soror dulcissima" (p. 131), donde Virgilio pone "cara", y un enamorado dice: "Dulcis appares omnibus, / sed es michi dulcissima" (p. 187). En los poemas en alemán: "vil süziz wip" (p. goo), "süze vrowe" (p. 189). Leo en el

$2 \tau$ "Welches sein Schicksal in Spanien war, müsste in einer besonderen Studie dargestellt werden" (p. 232). En el artículo de este autor puede verse una bibliografía de los principales estudios sobre el tema. Cf. también CuRTIus, op. cit., pp. 412-413, sobre el uso de dulce en el estilo ceremonial y epistolar.

28 Ya San Agustín había contrastado la "amaritudo mundi" con la "dulcedo Dei". Según Armknecht, la asociación con la Virgen se consuma en la segunda mitad del siglo XIII, al menos en Alemania: "süeziu maget wird in der zweiten Hälfte des 13 . und im 14. Jhd. die literarisch gebräuchlichste Formel für Maria" (p. 13o).

29 Es evidente la influencia de la escuela mística de San Anselmo, San Bernardo, Ricardo de San Victor, etc. Cf. ARMKNEchT, pp. 116-117, y Sister Lucy Tinsley, S.N.D., The French expressions for spirituality and devotion, Washington, D.C., 1953, pp. 28-3o, 48-51. En cuanto al "balsamo suavior" del antepenúltimo ejemplo, suave es prácticamente sinónimo de dulce; cf. ARMKNEcht, p. 117, sobre la distinción que hace San Isidoro entre ambos términos. 
Aliscans (ca. 1165) "dame Guiborc, dous cuer et douce amie" (p. 453), y pasajes análogos en los trovadores provenzales -"doussa dona", "ma duset' amia"-y en los poetas líricos franceses (cf. CARL APPel, Provenzalische Chrestomathie, Leipzig, 1912, y Heinimann, pp. 221-222).

El dulce referido a la mujer es también frecuente en Dante y se hace abundantísimo en Petrarca. Nos interesan particularmente las características antítesis: "dolce mia guerrera", y sobre todo el tan repetido "dolce nemica", que aparece siete veces en Petrarca mismo ${ }^{30}$.

A la influencia de Petrarca parece deberse la tardía aparición de la "dulce mujer" en la España del siglo xvi. Durante la Edad Media es raro ver en la Península el adjetivo dulce aplicado a una mujer terrenal: se le encuentra casi exclusivamente asociado a Cristo y a la Virgen. Berceo, según el decir de Lanchetas (Gramática y vocabulario de las obras de Gonzalo de Berceo, Madrid, I9oo), "prodiga el adjetivo dulce y sus derivados hasta hacerlo amargo e insoportable" (lo extraño es que no lo usa mucho para la Virgen en los numerosos cantos dedicados a ella). En Berceo (Milagros, 27) encontramos la fórmula "mucho más dulces que la azúcar sabrosa" (se refiere a los milagros mismos), variante de otra más comúnmente usada en la Edad Media española en contexto religioso: "más dulce que la miel"; asi, Alfonso el Sabio que usa poco el dulce, dice en una de sus Cantigas que Santa María "deu-lle tal comuyon / que foi mais doce ca mel" (Alfonso el Sabio, ed. A. Solalinde, Madrid, 1922, t. 1, p. 38). Y Juan Ruiz, hablando de la Pasión, dice que "las llagas que l' llagaron / son más dulces que miel..." (1065) (cf. nota 39). El Arcipreste habla además de Cristo como "del mundo dulçor" (1056) y "tu Fijo duz" (1055, 1639), y se dirige a la Virgen diciendo "En dulçor maravillosa, / ¡O María!" (1667).

Aunque hay epítetos más usados (glorioso, sagrado, precioso...), dul. ce aparece con cierta frecuencia en la poesía devota del siglo xv. Cristo es "muy dulce y benigno Señor" (R. Foulché-Delbosc, Cancionero del siglo $x y$, núm. 167), "mi dulce dulzor" (ibid., t. 1, p. 441b), y aun "dulcísima dotrina" (ibid., núm. 11); la Virgen es "preciosa de muy dulçe aspecto" (ibid., núm. 3o7) y "dulçor de los dulçores" (ibid., núm. 2), frase que recuerda la fórmula bernardina "omni dulcore dulcior". Por extensión se habla de "dulce piedad", "dulce caridad", "áruol dulçe de verdad" (la cruz, ibid., núm. 108), y Juan de Padilla evoca los "dulces dulzores" de la bienaventuranza (ibid., t. 1, p. 447a). Una estrofa típica es: "O dulcedumbre de mi corazón, / y ¿cómo no lloro con esta pintura, / viendo llorosa tu dulce figura, / siendo la fuente de consolación?" (ibid., t. 1, p. 437a). El epíteto abunda en la breve sección de "Obras de devoción” del Cancionero general de Hernando del Castillo (1511); lo encontramos referido a la Virgen, a Jesús y aun a los santos ${ }^{31}$.

3o Cf. Kenneth McKenzie, Concordanza delle "Rime" di Francesco Petrarca, Oxford, 1912. Con acierto decía un español, dirigiéndose al Amor: "Petrarca te define por contrarios, que eres un fuego escondido, una agradable llaga, un sabroso veneno, una dulce amargura, una deleitable dolencia, un alegre tormento, una dulce y fiera herida, una blanda muerte" (SANCHO DE MUÑón, Lisandro y Roselia, [1542], Madrid, 1872, p. 278 ).

${ }^{31}$ Cito por la edición facsimilar de A. Rodríguez-Moñino, Madrid, 1958. De la 
El siglo xvi continúa por la misma senda. En el Cancionero espiritual de mediados de siglo, por ejemplo, dulce, dulcissimo, dulçor, dulcura aparecen a cada paso, en relación con Dios, con el Niño, con las llagas de Cristo, con el "pan de alegría", y sobre todo con la Virgen, que sigue siendo la "dulce" dama por excelencia". En cambio, ya a fines de siglo, en el Cancionero de Nuestra Señora (1591; ed. A. Pérez Gómez, Valencia, 1952) el epíteto sólo aparece tres veces, referido a Cristo ${ }^{33}$. Sin duda, el gusto personal del poeta intervendría en el empleo del adjetivo para los seres sagrados.

Donde España se aparta decididamente de los demás países europeos es en el uso profano del concepto. Durante la Edad Media, y hasta el siglo xvI, se nota una clara resistencia a emplear dulce referido a la mujer ${ }^{34}$. La lírica medieval española apenas conoce el concepto de la dulzura del carácter femenino. En el corpus de las "cantigas d'amigo" gallego-portuguesas el epíteto no aparece una sola vez. Es verdad que los poetas hispanos medievales son en general más parcos en el empleo de epítetos que los demás europeos. Menéndez Pidal, señalando precisamente un caso de dulce en las chansons de femme francesas ("amis douz"), observa que los peninsulares son "más lacónicos" ("La primitiva lírica europea", $R F E, 43,1960$, p. 313). En Juan Ruiz asoma, junto al uso religioso, el profano: "aquel buen mançebo dulçe amor syn fallyr" (850); la dueña chica "con doñeo es más dulçe que açúcar nin flor" $(\mathbf{1 6 1 4})^{35}$. Pero el caso es excepcional dentro de España.

Todavía entre los poetas cortesanos del siglo xv el uso del adjetivo dulce aplicado a la mujer es infinitamente más moderado que el que se observa en los trovadores provenzales, en los poetas franceses y en Petrarca. Ausias March, al parecer tan hondamente influido por Petrarca, no lo usa una sola vez en sus muchas poesías amorosas, aunque habla repetidas veces de lo "agridulce" del amor, concepto tan grato a los trovadores y a Petrarca (Les obres, ed. A. Pagès, Barcelona, 1912, t. 1,

Virgen se dice "dulce madre" (fol. 8v), "dulcís siempre María" (fol. 2ov), "dulcedo esperança" (20r), y se habla de sus "dulces redes" (3r) y del "dulce parto de Jesús" (Iv); Cristo es "dulce flama sin ardor" (17r), "Señor dulce gracioso" (19v), dotado de "dulce memoria" (ibid.; cf. el himno de San Bernardo, "Iesu dulcís memoria"). En otra sección se habla del "dulce San Juan" (76r), y Juan de Padilla, en sus Doce triunfos, llama "dulce Maestro", "dulce Guía", etc. a los apóstơles.

\$2 Cancionero espiritual (1549), ed. B. W. Wardropper, Valencia, 1954. La Virgen es "muy dulcissima esposa / virginal" (p. 28), es "ramo de vida y dulçura" (p. 37), es "un dulçor / muy más dulce que la miel" (p. 42; cf. nota 39), "dulçor sin amargura" (p. 46), pero también "sabrosa sal y dulçura" (ibid.), etc. (cf. pp. 49, 53, 55, $5^{8}, 59$ ). Dos veces se habla del "dulce Niño" (pp. 72, 73), muchas del "dulccor" o la "dulçura" de Dios (pp. 125, 127, 173, 174, 177, 192, 199). En la p. 201, la "dulçura" de San Juan; p. 119, los "dulçores" de las llagas de Cristo.

s3 "Tu dulce y amado hijo Iesu Christo" (p. 112), "dulce hijo" (p. 12,1), "dulce fruto / del vientre sagrado" (p. 143).

3* No me ocuparé aquí del concepto abstracto 'dulzura de amor' ni de otros parecidos, pues aunque se relacionan hasta cierto punto con la dulzura de la amada o del amado, se refieren más a la sensación que experimenta el ser que ama que al carácter de la mujer, que es el que aquí nos interesa. Alguna vez se llama al ser amado "dulce amor", pero esto es poco frecuente.

s5 Además dice Trotaconventos de Doña Endrina: "óyeme dulcemente" (8o8), pero el adverbio se refiere aquí a lo vencida que está Endrina. 
p. 247 ; t. 2, pp. $88,97,107,171,175$ ). Los poetas de cancionero castellanos se contentan en general con los adjetivos linda, fermosa, graciosa, gentil, garrida, lozana, galana, discreta, etc. (cf. "una señora... / flor de todas las mugeres, / más hermosa que ninguna, / más discreta, más galana / y más graciosa, / a quien hizo la fortuna / más pomposa y más ufana / y más preciosa", Cancionero general, ed. cit., fol. I 74 r).

En el Cancionero de Stúñiga sólo encontramos un "mi dolçe amiga" (ed. Madrid, 1872, p. 51), y un "de las que han gran dolçura, / galanes, non vos fiés" (p. 249). En el de Baena: "vuestra dulçor" (ed. Madrid, 1851, p. 17), y "es más dulce que la miel / el rroçío que dél [del vergel] mana" (p. 537), donde tras la dulzura del rocío parece esconderse la dulzura sensual de la dama. En el Cancionero de Palacio vuelve a aparecer la nota negativa que vimos en el de Stúñiga: "En la su muy grant dulçura, / amigo, no vos fiedes" (ed. Barcelona, 1945, p. 212 ); además "mi dulçe senyora" (p. 287) y, a propósito de Eva, "dulce flor de paraíso" (p. 306). Es muy instructivo el gran Cancionero general de 1511: hemos visto la abundancia del epíteto en la breve sección de "Obras de devoción"; pues bien, entre el enorme número de poesías amorosas sólo una vez se encuentra dulce referido a una mujer, en la fórmula "mi bien y mi dulce amiga", que Santillana (fol. $27 \mathrm{v}$ ) puede haber tomado de la poesía provenzal"36.

Es interesante un poema de Francisco Vaca en el mismo Cancionero general (fols. $75 \mathrm{v}$ ss.). Increpa a Antón de Montoro por haber loado a la reina Isabel con términos reservados para la Virgen, en vez de emplear "la forma que fuera razón tener para loar ala reyna"; a ella le convienen expresiones como "graciosa", "generosa", "superiora", "virtuosa", de "hermosa fación", "con sobra de discreción", "con un valor tan profundo", etc. (fol. 77r); la Virgen, en cambio, es "dulce más que miel" 37 .

Es evidente que para el poeta medieval español la dulzura estaba demasiado asociada con el carácter de la Virgen y con el de su Hijo. Decir de una dama que era dulce debía tener un sabor un tanto irreverente; aun los poetas amatorios del siglo xv, tan conocidos por sus irreverencias, lo evitarían por ese motivo, como lo evitaría fray Luis en el xvi (cf. nota 39). Recuérdese que Lope de Vega eludió, por razones análogas, el nombre de Maria para sus damas ${ }^{38}$. Acaso sea algo más que un azar el que, al remedar la fórmula petrarquesca (o trovadoresca) "dolce mía guerrera", el poeta Suárez diga, dirigiéndose a las mujeres: "soys una tan dulce guerra" (ibid., fol. 82r): despersonaliza la expre-

${ }^{36}$ En los sonetos de Santillana hay varios dulce de clara ascendencia petrarquesca; por ejemplo, "O dulce esguarde...", Foulché, núm. 181 (cf. Petrarci, Rime, núms. $183,253,273$, etc.). La influencia de Petrarca es también patente en el famoso Diálogo de Rodrigo Cota, que desarrolla el tema de lo "agridulce" del amor; en una esparsa del propio Cota el amor es "hiel salerosa, dulce agrura" (Cancionero general, fol. 7 ov).

${ }_{37}$ Nunca he visto que se llame dulce a la reina. Villasandino, al pedir "vistuario y mula" al rey, lo llama irónicamente "O muy dulçe egualador", equiparándolo con Dios (Foulché, núm. 758).

${ }^{38}$ Creo que para explicar los no muy numerosos Dulces históricos (y los cultis. mos Dulcidius, Dulcina, relacionados con lat. Dulcis y Dulcius) que cita Lapesa ("Aldonza-Dulce-Dulcinea", art. cit., pp. 49-52), basta tener en cuenta que en la vida cotidiana es posible usar una cualidad o un nombre comúnmente asociados con la 
sión. Podríamos decir que, además del tabú religioso, lo que se opone al empleo de dulce referido a la amada es el mismo tono abstracto y conceptual de la poesía de cancionero, ajena al trato personal e íntimo, y quizá también en parte la "reclusión en el propio espíritu" de que habla Lapesa (Trayectoria poética de Garcilaso, Madrid, 1948, pp. 2123, 29).

Pero aun ahí donde el tono no es abstracto ni conceptual, en la poesía de tipo popular, es raro el dulce. En ningún romance viejo lo encontramos aplicado a una mujer; incluso el "dulce amigo" sólo aparece en la refundición tardía del romance de Gerineldo (Wolf y HoFmann, Primavera, núm. 161a); ahí mismo se habla de los "dulces halagos" amorosos, que hacen pareja con los "dulces besos" de algunos romances (por ejemplo, el del Conde Claros, Primavera, núm. 19o) y con el "dulçor" de que gozan Oriana y Amadís en otro romance tardío (Cancionero de romances s.a., fol. $264 \mathrm{r}$ ).

El panorama no cambia en las obras en prosa. En el Amadis, cuya adjetivación es tan pobre y cuyas damas son todas "fermosas", no hay ninguna mujer dulce (el adjetivo se dedica, en cambio, a describir los placeres de la comida, por ejemplo: $B A E$, t. 4 o, p. 84a). Tampoco Diego de San Pedro llama dulce a la mujer en su Cárcel de amor. $\mathrm{Ni}$ siquiera Melibea recibirá directamente el calificativo, aunque ya en la Celestina encontramos varias veces el dulce asociado a la mujer y con un franco matiz sensual: Calisto habla de la "dulce carne" de las manos de Melibea (ed. Cejador, Madrid, 1954, t. 1, p. 56), de "palabras de aquella dulce boca" (t. 1, p. 226), del "dulce puerto" de su amor (t. 2, p. 117); además: el "dulce vergel" y "aquel parayso dulce" (t. 2, p. 127).

Se va preparando un cambio. Creo vislumbrar en los poetas líricos de la tardía Edad Media una como lucha por desasirse de la imagen de la Virgen como objeto principal de su afecto pasional, lucha no terminada hasta el auge del Renacimiento, y aun entonces no en todos (cf. nota 39). He aquí unos pasajes que juzgo característicos en este sentido: Juan de Mena dice "después de la Virgen María, / ninguna tal como vos" (Foulché, núm. 18); Lope de Stúñiga, "que, par Dios, después de aquella / devota Virgen María, / delas otras sois estrella: / nunca nasció tal donzella / como vos, señora mía" (ibid., núm. 969).

El cambio se produce en el siglo xvr. Por la poderosa influencia de Petrarca, según apuntábamos, comienza a cundir entre los poetas el dulce referido a la mujer amada. La huella de Petrarca se ve, entre otras cosas, en la abundancia de fórmulas antitéticas del tipo "dulce enemiga". Y a la influencia de Petrarca se añade la de Virgilio, sobre todo la del "dulces exuviae" de la Eneida, IV, 652 y la del "Nerine Galathea, thymo mihi dulcior Hyblae" (Égl. VII, 37) ${ }^{39}$.

Virgen, mientras que no siempre es lícito ni conveniente hacerlo en la literatura. Cf. el caso de Lope y también el de Quevedo: "María de la Guía" queda reducido a "Tal de la Guía" en la edición censurada del Buscón de 1626.

so Un estudio reciente destaca la influencia de este último pasaje de Virgilio en la poesía renacentista española: MARCiAL José BAYo, Virgilio y la pastoral española del Renacimiento. $1480-1530$, Madrid, 1959, pp. 53, 60, 216 . El verso fue traducido por varios poetas e imitado por muchísimos. Recordemos dos traducciones: la de 
Garcilaso habla ya de "dulces y graciosisimas doncellas" (Égloga II, v. 624), cosa que habría sido imposible en la Edad Media española, para la cual la única doncella "dulce" era la Virgen. Habla también de "dulce esposa" (ibid., vs. 1417-1418), de "dulce amigo" (Soneto XIX; Égloga II, v. 414; Elegia I, v. 62), de "dulce hermano" (Elegia I, v. 49), de "dulce(s) prenda(s)" (Éloga I, 342; Soneto X), "dulce fruto" (Elegia $I I, 107)$; finalmente, la famosa fórmula virgiliana, "Flérida, para mí dulce y sabrosa...", en la Égloga III, vs. 305-306 (cf. nota 39). En cuanto a Fernando de Herrera, probablemente más petrarquesco que virgiliano, véanse en la edición de Madrid, 1914, las páginas 69, 72, 74, 78 , $105,108,133,190,219,225235$, etc., donde se destacan los usos antitéticos a la manera de Petrarca ("dulces engaños", etc.).

El epiteto abunda en muchos seguidores de Garcilaso; lo vemos a menudo en Gutierre de Cetina, si bien con un uso algo indirecto (ed. Madrid, 1895 , t. 1, pp. $69,73,78,90,179,218,284)$; su expresión predilecta es precisamente el "dulce mirar" de su famoso madrigal (cf. t. 1 , pp. 3, 7o, 128, 132, 208, 276; t. 2, pp. 150, 158), el cual como el "dulce esguarde" de Santillana, debe de proceder del "dolce sguardo" de Petrarca (cf. nota $3^{6}$ ). En el Cancionero llamado Flor de enamorados, de ${ }_{15} 5_{2}$ (ed. A. Rodríguez-Moñino, Valencia, 1954) encontramos atisbos de Petrarca, aunque no muchos, y de Garcilaso: "dulce amigo" en un soneto sobre la "hermosa Hero", de influencia garcilasiana (fol. 655 r); el soneto de Garcilaso "Passando el mar Leandro el animoso" (fol. 64v); "tan dulces vuestros tiros" (los de la dama, fol. 8ov); "dulce brio" (de un hombre, fol. 131r); "dulce loable figura" (fol. 13iv s.; cf. Petrarca: "...dolce, umile, angelica figura", Rime, 265); y una traducción del famoso poema "De la dulce mi enemiga" de Serafino Aquilano (fol. $37 \mathrm{v})$ comentado supra, nota 25. También abunda dulce en el Cancio-

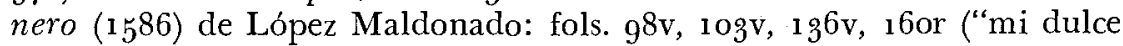
Amarili"), 162r ("dulce pastora"), $169 \mathrm{v}, 185 \mathrm{v}$ (para su "dulcíssima enemiga", $78 \mathrm{v}$, cf. nota 25 ).

Por lo demás, el epíteto ha ido penetrando el ámbito de lo pastoril, con el cual, como hemos visto, cuadra tan admirablemente. Es significativo el trueque que da el pastoril Jorge de Montemayor a unas palabras del abstracto Ausias March; donde éste decía "Plena de seny, no pot Deu a mi dar / fora de vos que descontent no camp" (op. cit., t. 1, p. 196), Montemayor traduce: "Dulce señora mía: yo no veo / plazer sin vos que pueda dar contento" (Traducciones castellanas de Ausias March en la Edad de Oro, ed. M. de Riquer, Barcelona, 1946, p. 137), suprimiendo el Dios e introduciendo un dulce. El mismo Montemayor inclu-

Encina, "Dulce me eres, Galatea / más que miel de tomillar", y la de fray Luis de León, "Nerine Galatea más sabrosa / que el tomillo hibleo". Nótese que fray Luis, como buen clérigo, suprime el dulce, tal vez recordando la costumbre medieval de adjudicarlo principalmente a la Virgen. Por otra parte, véase el estudio de María Rosa LlDA, “Transmisión y recreación de temas grecolatinos. II, El esquema *Flérida, para mí dulce y sabrosa / más que la fruta del cercado ajeno...»", $R F H, 1$ (1939), pp. $5^{2-63}$, donde salta a la vista la frecuencia - un noventa por ciento de los casoscon que los poetas imitadores del esquema citado eluden el dulce original de Virgilio, sustituyéndolo por "hermosa", "resplandeciente", "graciosa", "lozana", etc., etc., a pesar del inmenso e indudable prestigio del verso de Garcilaso. 
ye en los versos de la Diana un "muy dulce señora mía" y un "ven, mi pastora dulce" (Madrid, 1946, pp. 86, 251), y en su Cancionero, un "dulce Ninpha mía" y un "mi pastora dulce" (ed. Madrid, 1932, p. 436; no he examinado toda la obra). En el prólogo a Los pastores del Betis de Gonzalo de Saavedra un poeta llama al autor "dulcíssimo pastor", y en otro poema dedicatorio de un libro pastoril, La enamorada Elisea (1594) de Gerónimo de Covarrubias, encontramos la frase "dulcissima Elisea" (citado por A. G. Reichenberger, "Competitive imagery in Spanish poetry”, $A I O N-R$, 4, 1962, p. 91). Constantemente vemos el epíteto acompañando a nombres pastoriles como Tirseo, Alisa, etc. y a términos como pastora y ninfa. Por supuesto, lo encontramos menos a menudo en la prosa; quizá es Cervantes el que más emplea dulce -con acento paródico- en la literatura prosística no religiosa. Y el nombre mismo de Dulcinea debe encuadrarse en todo este movimiento español, en cuyo origen está Petrarca y más directamente Garcilaso.

Es interesante el caso del Romancero general de 1600: hay abundancia de mujeres "dulces", y no sólo en los romances pastoriles. El más frecuente es "dulce esposa" (ed. A. González Palencia, Madrid, 1947, núms. 3o, 179, 414); además, el adjetivo acompaña a "hermana" (685), "picarilla" (91), "madre mía" (84), "pastora mía" (445), "enemiga mía" (310), "Alisa mía" (364), "Leonida" (517), "amiga de mis ojos" (169); otros casos: "mora sabrosa y dulce" (182), mora "no menos dulce que bella" (430), dama "dulce en estremo", dama "más dulce que la miel" (309), "mozuelas agridulces" (345); y junto a ellos, el superlativo, "dulcísima Valenciana" 40 . Varias veces aparece referido a un hombre: "dulce amigo" (493), "amado dulce" (345), "mi dulce Tirseo (Polidoro)" (448, $593)^{41}$. $\mathrm{Y}$ siete veces nos encontramos con el garcilasiano dulce(s) prenda(s): núms. $33(=177), 213,283,649,671,707,772$.

so El superlativo de dulce merecería un estudio aparte. En la poesía latina medieval de tema religioso es sumamente frecuente. En el Oxford book of medieval Latin verse, por ejemplo, encontramos "amor Yesu dulcissimus" (p. 349) y "dulcissima" referido a un alma (p. ${ }_{15} 8$ ). Armknecht recoge, además de los citados arriba, otros ejemplos, como "O dulcissima atque amantissima mater", "O dulcissime amator, complexator". Según Lanchetas, el primer dulcisimo español se aplica a Cristo ("Del mio fiio dulcíssimo") y deriva probablemente de San Bernardo ("Fili dulcissime"; véanse en Lanchetas las observaciones sobre el superlativo en Berceo). Ya hemos comentado la abundancia de la forma en los Carmina Burana. En España, en cambio, dulcisima no parece usarse nunca durante la Edad Media referido a una mujer (es verdad que los superlativos sintéticos son en general escasos en el romance de la Edad Media). Todavía en el Renacimiento se usa sólo por excepción. Lope de Vega emplea bastante el superlativo para referirse a Cristo y a la Virgen en los Pastores de Belén, novela pastoril a lo divino, mientras que en la Arcadia casi no aparece la forma. Evidentemente hay, pues, un eco de la dulzura de la Virgen en el "dulcísima Dulcinea" de Cervantes. -En cuanto a la fórmula "más dulce que la miel (que el tomillo, etc.)", la hemos visto aplicada a Cristo y a María en la Edad Media _Berceo, Alfonso X, Juan Ruiz - y durante el Renacimiento _Cancionero espiritual de 1549--; también la hemos visto usada en contexto no religioso: en el Arcipreste de Hita (a propósito de la dueña chica), en el Cancionero de Baena (el rocío del vergel) y después -por influencia de Virgilio- en Juan del Encina ("Dulce me eres Galatea...") y en Garcilaso ("Flérida, para mí..."). La comparación llega a ser bastante frecuente en la poesía amatoria del Renacimiento. No está en Petrarca, como tampoco el superlativo.

12 En un romancillo (núm. 543) se jacta Martigüelo de ser "en gusto y talle / tan dulce...". Si ya en la Edad Media se podía hablar de "amis doux", el ideario 
Por otra parte, la moda del epíteto dulce no se extendió por todo el ámbito de la poesía renacentista española. Puede no extrañar su ausencia en Castillejo, pero sí en poetas italianizantes como Boscán o Diego Hurtado de Mendoza, que lo emplean muy poco; Francisco de Aldana lo aplica sobre todo al hombre; Hernando de Acuna no lo usa ni una sola vez en sus Varias poesias (Madrid, 1954); es raro en Pedro de Padilla y más raro en Francisco de Rioja. ¿Cómo se explica esa desigualdad en el uso de dulce? ¿Mera casualidad o idiosincrasia personal? Nuestra lista es, desde luego, muy incompleta. Tal vez un estudio detallado del fenómeno en el Siglo de Oro vierta alguna luz sobre un problema del Renacimiento español: sobre la famosa "escisión" espiritual que empieza en el siglo xvi.

HERMANN IVENTOSCH

State University of New York.

de la Ldad de Oro y del Renacimiento favorecía aún más la aplicación de ese atributo a los hombres. Recuérdense el "dulce amigo" de Garcilaso (y del romance de Cerineldo) y su "dulce hermano", lo mismo que el "dulcíssimo pastor" de Gonzalo de Saavedra. Es claro que ciertos nombres de pastores, asi como el creciente uso del adjetivo dulce reflejan esa fe en los hombres, ese "humanismo" tan grato al Renacimiento y tan arraigado en Cervantes. 